\title{
Analysis of geomagnetic storms in South Atlantic Magnetic Anomaly (SAMA)
}

\author{
Júlia Maria Soja Sampaio, Elder Yokoyama, Luciana Figueiredo Prado
}

Copyright 2019, SBGf - Sociedade Brasileira de Geofísica

This paper was prepared for presentation during the $16^{\text {th }}$ International Congress of the Brazilian Geophysical Society held in Rio de Janeiro, Brazil, 19-22 August 2019.

Contents of this paper were reviewed by the Technical Committee of the $16^{\text {th }}$ International Congress of the Brazilian Geophysical Society and do not necessarily represent any position of the SBGf, its officers or members. Electronic reproduction or chresent any position of the SBG its oflices or members. Electonic reproduction of the Brazilian Geophysical Society is prohibited.

\section{Abstract}

Geomagnetic storm is a major disturbance of Earth's magnetosphere resulted from the interaction of solar wind and the Earth's magnetic field. This disturbance depends of the Earth magnetic field geometry, and varies in terms of intensity from the Poles to the Equator. This disturbance is quantified through geomagnetic indices, such as the Dst and the $A E$ indices. $A E$ measure the disturbance on auroral zone while Dst measure the disturbance on mid-latitude regions. As Dst and $A E$ indices vary according to the geomagnetic field geometry, in this framework, fluctuations in the geomagnetic field can occur under the influence of the South Atlantic Magnetic Anomaly (SAMA). In this ongoing study proposes to investigate the geomagnetic storms at the region of SAMA influence. For this we will use a database of the Vassouras'Magnetic Observatory and AE and Dst indices. Our first impressions and perspectives will be discussed.

\section{Introduction}

Geomagnetic storm is a major disturbance of Earth's magnetosphere resulted from the interaction of solar wind and the Earth's magnetic field. This perturbation can be quantified through geomagnetic indices as the Dst and the $\quad \mathrm{AE}$ (https:// www.swpc.noaa.gov/phenomena/geomagnetic-storms).

The Dst index measures the magnitude of the current associated to the symmetry disturbance in the geomagnetic field (MANDEA; KORTE, 2011).

The $A E$ index represents the overall activity of the electrojets (MANDEA; KORTE, 2011) through geomagnetic variations in the horizontal component $H$ observed at 12 selected observatories along the auroral zone in the northern hemisphere.

Dst and $A E$ indices allows the classification of geomagnetic storm as sporadic and recurrent. Sporadic geomagnetic storms present a chain of substorms with a sharp start and shorter duration whilst recurrent storms display a high level of background perturbations (SHADRINA, 2017).
Moreover, Dst and $A E$ indices may vary according to the geomagnetic field geometry, such as polar to intermediate latitudinal field variations. In this framework, fluctuations in the geomagnetic field can occur under the influence of the South Atlantic Magnetic Anomaly (SAMA). The SAMA is a region of minimum geomagnetic field intensity values at the Earth's surface (Figure 1), and its dipole intensity is decreasing along the past 1000 years (Terra-Nova et. al., 2017).

In this study we will compare the behavior of the types of geomagnetic storms basis on $\mathrm{AE}$ and Dst indices.

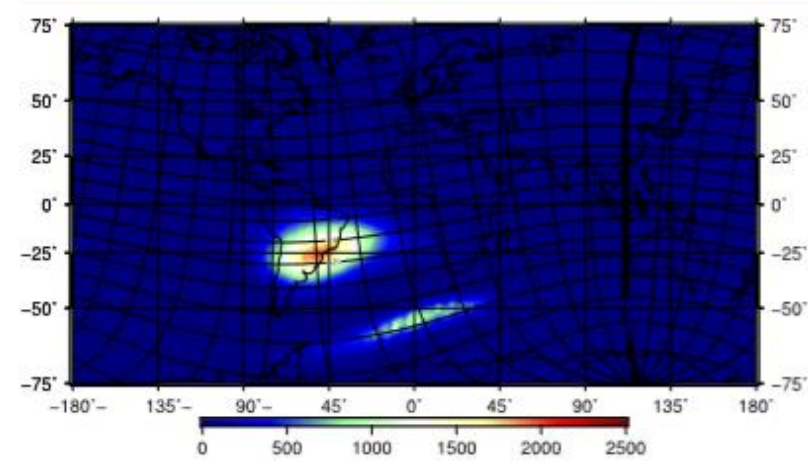

Figure 1 - Map of the geomagnetic field with eccentric dipole grid representation overlaid (DOMIMGOS, et. al., 2017).

\section{Method}

The Dst and $\mathrm{AE}$ indices magnetospheric data were obtained from the International Service of Geomagnetic Indices (http://isgi.unistra.fr/data download.php). The dates have the format of IAGA - 2002, soured of data WDC for geomagnetism, Kyoto, Japan with interval of 1 hour and unit $1 \mathrm{nT}$.

In this study, we applied the parameter $\mathrm{k}$ to differ both types of storms (sporadic and recurrent) defined as $k=(\Delta$ Dst)/ ( $\left.\sum \mathrm{AE}\right) . \Delta \mathrm{Dst}$ is the low latitude Dst-index amplitude, and $\sum A E$ is the sum of high latitude index $A E$ for the main phase of the storm. $k$ values below 0.010 refer to sporadic storms, and $k$ values above 0.015 refer to recurrent storms (SHADRINA, 2017).

Have been chosen two geomagnetic storms with different features between several to deepen the studies. The Table 1 show four different geomagnetic storms. Their parameter used were main phase duration $(\Delta t)$, low latitude Dst-index amplitude ( $\Delta \mathrm{Dst})$, class of the stomr (Ssmall, M-moderate), sum of the high latitude index $A E$ for the main phase of the storm ( $\Sigma \mathrm{AE})$ and type (sporadic or recurrent) (SHADRINA, et al., 2014). 
Table. 1- Dates and geomagnetic storm parameters

\begin{tabular}{|l|l|l|l|l|l|}
\hline $\begin{array}{l}\text { Date } \\
\text { (dd.mm.yyyy) }\end{array}$ & $\Delta \mathrm{t}$ & $\Delta$ Dst & Class & $\sum \mathrm{AE}$ & Type \\
\hline 23.10 .2003 & 12 & 48 & $\mathrm{~S}$ & 3746 & spor \\
\hline 30.10 .2009 & 20 & 54 & $\mathrm{M}$ & 3610 & spor \\
\hline 08.11 .2009 & 12 & 39 & $\mathrm{~S}$ & 3651 & rec \\
\hline 11.03 .2011 & 31 & 84 & $\mathrm{M}$ & 15153 & rec \\
\hline
\end{tabular}

Posterior steps of this research will include the use of the cross-wavelet transform to identify similarities and/or differences between the geomagnetic field observed in both high and intermediate latitudes. This parameter is important to study because the geomagnetic storm can be feel in different intensity in different latitudes because of the geomagnetic field.

The wavelet transform can be expressed as (e.g. Torrence and Compo, 1998)

$$
W(a, b)=\left\langle f(t), \psi_{a, b}(t)\right\rangle=\int_{-\infty}^{\infty} f(t) \psi_{a, b}^{*}(t) d t .
$$

Where $f(t)$ is a real function defined in time domain, $\psi(t)$ is the mother wavelet, $\psi_{\mathrm{a}, \mathrm{b}}(\mathrm{t})$ are the daughter wavelets. In this study we will use the Morlet wavelet because it is adequate to detect periodicities observed in geophysical signals.

\section{Results}

To evaluate the geomagnetic field variations during storms, we plotted the temporal evolution of Dst and $A E$ indices during two different time episodes, centered on October 30th 2003 (Figure 2) and November $08^{\text {th }} 2009$ (Figure 3). To capture the behavior of the storms, we considered eight days before and after the storm day. Both indices are given in $\mathrm{nT}$. Table 1 contains the parameters that define both storms detailed in Figures 2 and 3.

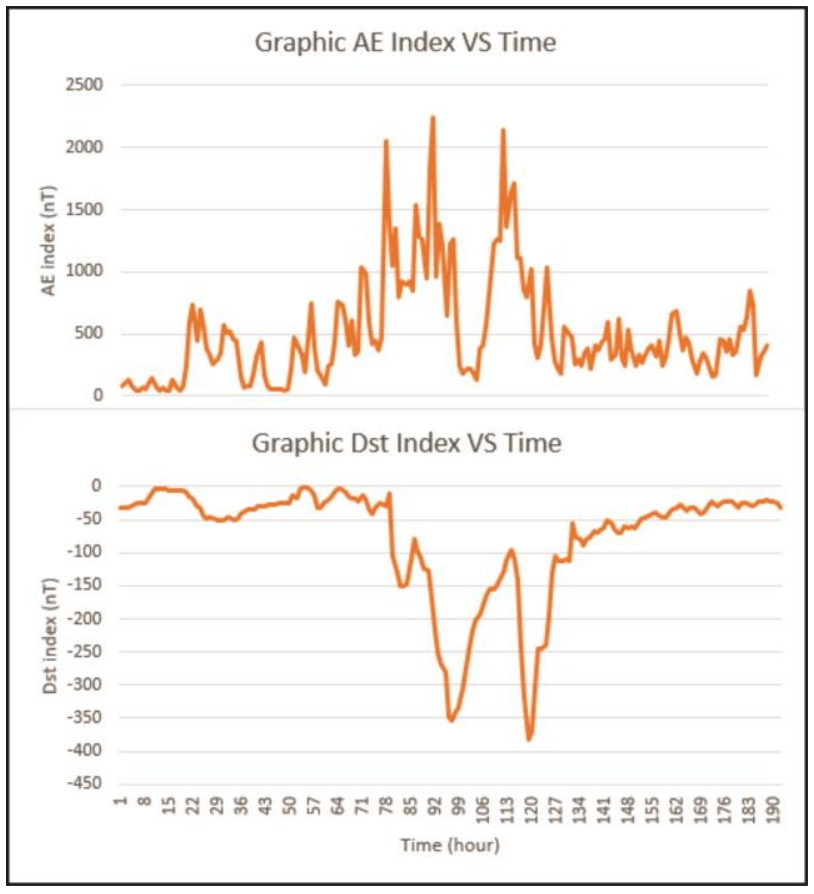

Figure 2 - shows how each index behaves before a sporadic geomagnetic storm occurred in Oct $30^{\text {th }} 2003$.

The geomagnetic storm observed in Figure 2 corresponds to the sporadic type as show in Table 1. Normally, the main phase has the period of 8 to 12 hours but in the graphic, we can interpret more than expect period. Probably this happing because the geomagnetic field delay to stabilize again.

At the graphic for $A E$ index we can observe a chaotic system with several peaks and three stronger than other reference of main phase.

At the graphic for Dst index it is possible to interpret all the values are negative but we have a two peaks stronger reference of main phase.

The Figure 3 is based on the dates from geomagnetic storm recurrent, as show in Table 1. 


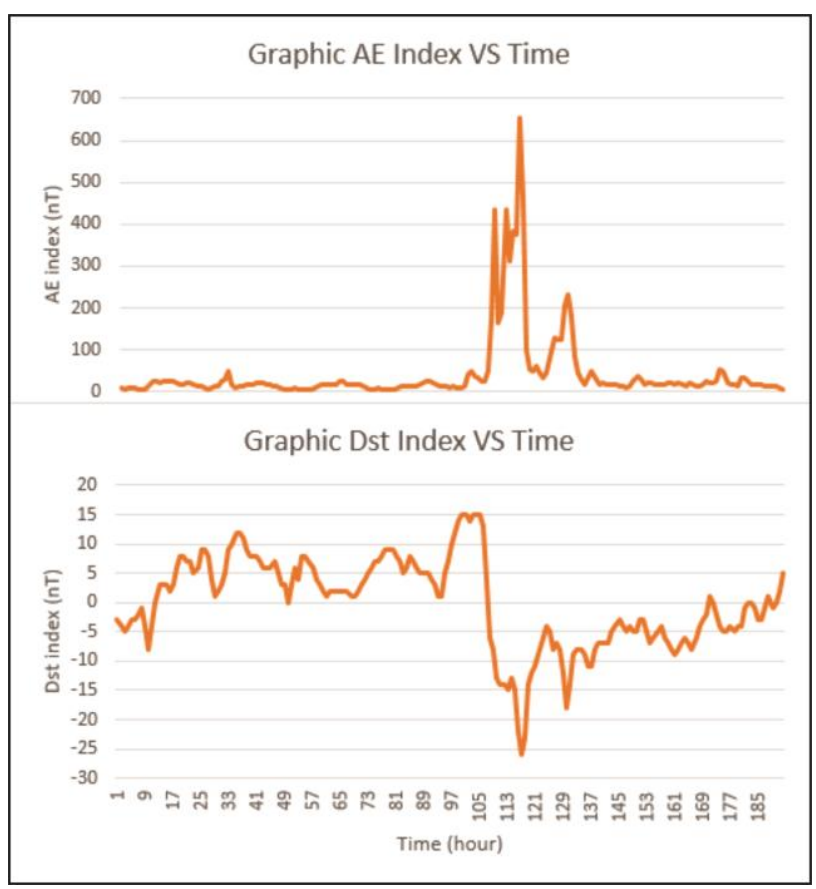

Figure 2 - shows how each index behaves before a geomagnetic storm occurred in Nov $0^{\text {th }} 2009$.

For this type of geomagnetic storm, recurrent storm, the main phase have period of 14 to 18 hours.

The measure for the $A E$ index is very punctual, it is possible perceive that the values are linear, but in the middle have one anomaly.

The values from Dst index are symmetrical, visually we have the same number from values negatives and positives. The peak positive followed from one peak negative show the main phase.

\section{Conclusions}

Both indices, AE and Dst are not calculate basis in South America. They measure are fundamental in others regions for this reason it is expected a different behavior for this index in South America due to SAA.

The parameter $\mathrm{k}$ show to be effective being a numerical indicator of geomagnetic storm type. Between storm types, recurrent storms have a shorter main phase and more intense compared with sporadic storm.

\section{Acknowledgments}

This study received financial support from Sociedade Brasileira de Geofísica (SBGf), and was financed in part by the Coordenação de Aperfeiçoamento de Pessoal de Nível Superior - Brasil (CAPES) - Finance Code 001, number 88887.314387/2019-00.

J.M.S.S. is thankful to the University of Brasilia for the support and to E. Y. for the teaching and advising.

\section{References}

DOMINGOS, J. D., et. Al., The South Atlantic Anomaly throughout the solar cycle. Earth and Planetary Science Letters, 473 (2017) 154-163.

MANDEA, Mioara; KORTE, Monika. Geomagnetic Observations and Models, V. 5. Springer Science+Business Media B. V, 2011.

SHADRINA, Lyudmila P. Two Types os Geomagnetic Storms and Relationship Between Dst and AE Indexes, 2017.

SHADRINA, L.P.; SAMSONOV, S.N.; MANYKINA, V. I., Sporadic and Recurrent Geomagnetic Storm Responses in the Human Cardiogram, 2014.

TERRA-NOVA, Felipe; AMIT, Hagay; et al., Relating the South Atlantic Anomaly and geomagnetic flux patches 2017.

TORRENCE, c., Compo, G. P. A practical guide to wavelet analysis. Bulletin of the American Meteorological Society, 79(1), 1998. 